\title{
Beta ig-h3 promotes renal proximal tubular epithelial cell adhesion, migration and proliferation through the interaction with $\alpha 3 \beta 1$ integrin
}

\author{
Sun-Woo Park ${ }^{1}$, Jong-Sup Bae ${ }^{1}$, \\ Ki-San Kim ${ }^{3}$, Sun-Hee Park ${ }^{2}$, \\ Byung-Heon Lee ${ }^{1}$, Je-Yong Choi ${ }^{1}$, \\ Jae-Yong Park, ${ }^{1,2}$, Sung-Woo $\mathrm{Ha}^{2}$, \\ Yong-Lim Kim ${ }^{2}$, Tae-Hwan Kwon ${ }^{1}$, \\ In-San Kim ${ }^{1}$ and Rang-Woon Park ${ }^{1,4}$ \\ ${ }^{1}$ Cell and Matrix Biology National Research Laboratory \\ Department of Biochemistry \\ ${ }^{2}$ Department of Internal Medicine \\ School of Medicine, Kyungpook National University \\ 101 Dongin-dong, Jung-gu, Daegu 700-422, Korea \\ ${ }^{3}$ Department of Ophthalmology \\ School of Medicine, Keimyung University, Daegu, Korea \\ ${ }^{4}$ Corresponding author: Tel, 82-53-420-4822; \\ Fax, 82-53-422-1466; E-mail, nwpark@knu.ac.kr
}

Accepted 19 April 2004

Abbreviations: BSA, bovine serum albumin; ECM, extracellular matrix; pFN, plasma fibronectin; RPTECs, renal proximal tubular epithelial cells; TGF- $\beta$, transforming growth factor- $\beta$

\begin{abstract}
Betaig-h3 ( $\beta i g-h 3)$ is a secretory protein composed of fasciclin l-like repeats containing sequences that allows binding of integrins and glycosaminoglycans in vivo. Expression of $\beta i g$ h3 is responsive to TGF- $\beta$ and the protein is found to be associated with extracellular matrix (ECM) molecules, implicating $\beta i g-h 3$ as an ECM adhesive protein of developmental processes. We previously observed predominant expression of $\beta$ ig-h 3 expression in the basement membrane of proximal tubules of kidney. In this study, the physiological relevance of such localized expression of $\beta$ ig-h 3 was examined in the renal proximal tubular epithelial cells (RPTEC). RPTEC constitutively expressed $\beta \mathrm{ig}-\mathrm{h} 3$ and the expression was dramatically induced by exogenous TGF- $\beta 1$ treatment. $\beta$ ig-h 3 and its second and fourth FAS1 domain were able to mediate RPTEC adhesion, spreading and migration. Two known $\alpha 3 \beta 1$ integrin-interaction motifs including
\end{abstract}

aspartatic acid and isoleucine residues, NKDIL and EPDIM in $\beta i g-h 3$ were responsible to mediate RPTEC adhesion, spreading, and migration. By using specific antibodies against integrins, we confirmed that $\alpha 3 \beta 1$ integrin mediates the adhesion and migration of RPTECs on $\beta i g-h 3$. In addition, it also enhanced proliferation of RPTECs through NKDIL and EPDIM. These results indicate that $\beta i g-h 3$ mediates adhesion, spreading, migration and proliferation of RPTECs through the interaction with $\alpha 3 \beta 1$ integrin and is intimately involved in the maintenance and the regeneration of renal proximal tubular epithelium.

Keywords: adhesion; $\alpha 3 \beta 1$ integrin; $\beta$ ig-h3; migration; proliferation; renal proximal tubular epithelial cell

\section{Introduction}

Transforming growth factor- $\beta$ (TGF- $\beta$ ) has potent effects on the proliferation and differentiation of a variety of cell types as well as on the synthesis of the extracellular matrix (ECM). TGF- $\beta$ has been shown to play an important role in maintaining the renal histological structure as well as glomerular and tubular function (Sharma and Ziyadeh, 1994). Big-h3 is a cell adhesive protein whose expression is highly induced by TGF- $\beta$ in several cell types (Sharma \& Ziyadeh, 1995). Big-h3 transcript was detected in a variety of human and mouse tissues including uterine tissue, heart, breast, prostate, skeletal muscle, testes, thyroid, kidney, liver, and stomach (Yamamoto et al., 1993). An immunohistochemical study with bovine tissues showed that $\beta$ ig-h3 was detected in many tissues such as developing nuchal ligament, aorta, lung, cornea, spleen and kidney (Sharma et al., 1997). Big-h3 has four internal repeat domains named FAS1, which have a homology with a Drosophila neuroadhesion molecule, fasciclin-1 (Wolf and Ziyadeh, 1999). In previous reports we identified two cell adhesion motifs within the second and fourth FAS 1 domains of $\beta$ ig-h3 mediating human corneal epithelial cell adhesion (Kim et al., 2000b) and human keratinocyte adhesion, migration, spreading and proliferation (Bae et al., 2002) through interacting with $\alpha 3 \beta 1$ integrin. In addition, we demonstrated that $\beta$ ig-h3 has 
a fibrillar structure and interacts with several extracellular matrix proteins such as fibronectin and collagen (Kim et al., 2002). Big-h3 is also known to affect cell growth and differentiation (Skonier et al., 1994; Dieudonn et al., 1999; Kim et al., 2000a). As ßig-h3 has a function to mediate cell adhesion, migration, and proliferation and is highly induced by TGF- $\beta$, it may also play some potential roles in renal tissue injury and/or regeneration. There are several evidences which suggest critical role of $\beta$ ig-h3 in physiology and pathology of proximal tubular epithelium. An in situ hybridization study has revealed that $\beta$ ig-h3 mRNA is expressed in proximal tubular epithelial cells (particularly in the S3 segment) and in the juxtaglomerular apparatus, and that these mRNA levels in the kidney are upregulated in diabetes mellitus induced by streptozotocin (Gilbert et al., 1998). Recently, we reported that $\beta$ ig-h3 protein was predominantly expressed in close association with the basement membrane of the proximal tubule $S 3$ segment in both normal and diabetic rat kidneys (Lee et al., 2003).

Therefore the present study aims to elucidate the role of $\beta$ ig-h3 in proximal tubular epithelium and the effect of $\beta$ ig-h3 on adhesion, migration, and proliferation of renal proximal tubular epithelial cells (RPTECs) was investigated.

\section{Materials and Methods}

\section{Cell culture}

The human primary renal proximal tubular epithelial cells (RPTECs) were purchased from Clonetics (San Diego, CA) and were maintained in REGM medium (also from Clonetics). Only the cells of the 1 st and 2nd passages were used in experiments.

\section{Electrophoresis and Western blotting}

Confluent quiescent cells were incubated with TGF- $\beta 1$ (R\&D systems Europe Ltd, Abingdon, UK) or vehicle only. After incubation for $48 \mathrm{~h}$, medium was collected and lyophilized. Ten $\mathrm{mg}$ of each sample mixed with $2 \mu \mathrm{l}$ of sample buffer $(100 \mathrm{mM}$ Tris $\mathrm{pH} 6.8,200 \mathrm{mM}$ dithiothreitol, $4 \%$ SDS, $0.2 \%$ bromophenol blue, $20 \%$ glycerol). The samples were boiled for $5 \mathrm{~min}$ and separated by $10 \%$ sodium dodecyl sulfate-polyacrylamide gel then samples were transferred onto nitrocellulose (Amersham Bioscience Korea). Blocking was performed in $5 \%$ nonfat dry milk in PBS for at least $1 \mathrm{~h}$ at room temperature. The membrane was incubated for $2 \mathrm{~h}$ at room temperature with anti-human Big-h3 antibodies (diluted 1:2,000 in PBS), then washed and incubated for $2 \mathrm{~h}$ at room temperature with the peroxidase-conjugated anti-rabbit IgG antibodies (diluted 1:2,000 in PBS, Amersham Bioscience
Korea). Protein bands were identified using the ECL Kit (Amersham Bioscience Korea). The protein concentration in the supernatant was measured by the Bradford method using the Bio-Rad Protein Assay Kit (Bio-Rad, Hercules, CA) according to the manufacturer's protocol.

\section{Enzyme-linked immunosorbent assay measuring ßig-h3 levels}

96-well plastic flat microtiter plates (Corning, Corning, $\mathrm{NY}$ ) were coated overnight at $4^{\circ} \mathrm{C}$ with $0.5 \mathrm{~g} / \mathrm{ml}$ wild-type $\beta$ ig-h3 protein in $20 \mathrm{mM}$ carbonate-bicarbonate buffer ( $\mathrm{pH}$ 9.6) with $0.02 \%$ sodium azide. The plates were rinsed three times in PBS-0.05\% Tween-20 (PBS-T) and kept at $4^{\circ} \mathrm{C}$. Lyophilized culture media were pre-incubated with anti-human Big-h3 antibody (diluted 1:2,000 in PBS-T) in 96-well plastic round microtiter plates for $90 \mathrm{~min}$ at $37^{\circ} \mathrm{C}$, transferred to the pre-coated plate and incubated for $30 \mathrm{~min}$ at room temperature. The plates were rinsed three times in PBS-T and incubated for $90 \mathrm{~min}$ at room temperature with peroxidase-conjugated antirabbit IgG antibody (diluted 1:2,000 in PBS-T, Amersham Bioscience Korea). The plates were rinsed three times in PBS-T and incubated for $60 \mathrm{~min}$ at room temperature in the dark with $200 \mu \mathrm{l}$ of the substrate solution $(100 \mathrm{mg} / \mathrm{ml}$ o-phenylenediamine and $0.003 \%$ $\mathrm{H}_{2} \mathrm{O}_{2}$ ). After stopping the reaction with $50 \mu \mathrm{l} /$ well $8 \mathrm{~N}$ $\mathrm{H}_{2} \mathrm{SO}_{4}$, the absorbance was read at $490 \mathrm{~nm}$ using a Bio-Rad Model 550 microplate reader. The results shown are derived from 3 separate experiments with duplicates performed in each experiment.

\section{Cell adhesion and spreading assay}

Briefly, 96-well microculture plates (Falcon, BectonDickinson Labware Europe, France) were coated with proteins or peptides, diluted in PBS at $4^{\circ} \mathrm{C}$ overnight. Then, the plates were rinsed three times in PBS and uncoated surfaces were blocked with PBS containing $2 \%$ heat-inactivated $B S A$ for $1 \mathrm{~h}$ at $37^{\circ} \mathrm{C}$. The plates were rinsed again, and $2 \times 10^{4}$ RPTECs were added to each well in $100 \mu$ of culture medium. For preparation of cells, RPTECs were treated with $0.25 \%$ trypsin-EDTA for $5 \mathrm{~min}$ at $37^{\circ} \mathrm{C}$ and further incubated for another 5 to $10 \mathrm{~min}$ after removal of excess trypsin-EDTA solution. After incubation for $1 \mathrm{~h}$ at $37^{\circ} \mathrm{C}$, unattached cells were removed by rinsing twice with PBS. For quantification of attached cells hexosaminidase assay was performed. Attached cells were incubated for $1 \mathrm{~h}$ at $37^{\circ} \mathrm{C}$ in $50 \mathrm{mM}$ citrate buffer, $\mathrm{pH} 5.0$, containing $3.75 \mathrm{mM}$ p-nitrophenyl-N-acetyl$\beta$-D-glucosaminide (hexosaminidase substrate) and $0.25 \%$ Triton $X-100$. The reaction was stopped and color developed by the addition of $50 \mathrm{mM}$ glycine buffer, $\mathrm{pH}$ 10.4, containing $5 \mathrm{mM}$ EDTA. The ab- 
sorbance was measured at $405 \mathrm{~nm}$ in Bio-Rad Model 550 microplate reader. To determine cell area, $2 \times 10^{4}$ cells were applied to substates in 96 -well culture plates. The attached cells were fixed with $8 \%$ glutaraldehyde (Sigma, St. Louis, MO) and then stained with $0.25 \%$ Crystal Violet (Sigma) in $20 \%$ methanol (w/v). Cell area was measured using Image-Pro plus software (Media Cybernetics, Silver Spring, MD). Experiments were repeated twice in triplicate. Data are reported as the mean area at specific time points \pm SD.

\section{Migration assay}

The cell migration assay was performed using transwell plates (8 $\mathrm{mm}$ pore size, Costar, Cambridge, $M A)$. The under surface of the membrane was coated at $4^{\circ} \mathrm{C}$ overnight with $10 \mathrm{mg} / \mathrm{ml} \mathrm{BSA}$, fibronectin (FN) or Big-h3 protein diluted in PBS and then blocked with $2 \%$ BSA. The upper compartment was seeded with $3 \times 10^{5}$ RPTECs per well in $200 \mu \mathrm{l}$ medium. In some experiments, cells were preincubated with anti- $\alpha 3$ monoclonal antibody (P1B5) and anti- $\beta 1$ monoclonal antibody (6S6) from Chemicon (Temecula, CA) at 1 $\mathrm{mg} / \mathrm{ml}$ for $30 \mathrm{~min}$. After $6 \mathrm{~h}$ of migration, cells in the upper chamber of the filter were removed and nonmigrating cells on the top of the filters were removed with a cotton swab. RPTECs on the lower side of the filter were fixed with $8 \%$ glutaraldehyde (Sigma) and stained with $0.25 \%$ crystal violet (Sigma) in $20 \%$ methanol (w/v). Each experiment used duplicate wells, and within each well counting was done in nine-randomly selected microscopic high power fields $(\times 200)$.

\section{Inhibition assay}

To identify the receptor of RPTEC for $\beta$ ig-h3, monoclonal antibodies to different types of integrins (Chemicon) were preincubated individually with RPTECs in $0.05 \mathrm{ml}$ of incubation solution $\left(2 \times 10^{5}\right.$ cells $\left./ \mathrm{ml}\right)$ at $37^{\circ} \mathrm{C}$ for $30 \mathrm{~min}$. The preincubated cells were transferred onto plates precoated with $\beta$ ig-h3 proteins and then incubated further for $1 \mathrm{~h}$ at $37^{\circ} \mathrm{C}$. Attached cells were then quantified as descried above.

\section{Antibodies}

The anti-human $\beta$ ig-h3 antibody used has been characterized previously (Lee et al., 2000). To make an anti-human $\beta$ ig-h3 antibody, recombinant human Big-h3 protein was prepared. Rabbits received a subcutaneous injection of the protein $(200 \mu \mathrm{g})$ in Complete Freund's Adjuvant (Sigma) followed by four immunizations spaced by 3 weeks with $200 \mu \mathrm{g}$ protein in Incomplete Freund's Adjuvant (Sigma). Antibody titers were monitored by immunoblot analysis using the recombinant $\beta$ ig-h3 protein. The antiserum was further purified by Protein A affinity chromatography
(Amersham Biosciences, Uppsala, Sweden) according to the manufacturer's protocol. The specificity of the anti-human $\beta$ ig-h3 antibody was tested by Western blotting (data not shown). Anti-human integrin monoclonal antibodies utilized for function-blocking assay were $\alpha 1$ (FB12), $\alpha 2$ (P1E6), $\alpha 3$ (P1B5), $\alpha 4$ (P1H4), $\alpha 5$ (P1D6), $\alpha 6$ (GoH3), $\alpha \mathrm{V}$ (P3G8), $\beta 1$ (6S6), $\beta 2$ (P4H9), $\alpha v \beta 3$ (LM609) and $\alpha v \beta 5$ (P1F6) from Chemicon.

\section{Proliferation assay}

Twenty four-well culture plates were coated with proteins or peptides, diluted in PBS at $4^{\circ} \mathrm{C}$ overnight. Then, the plates were rinsed three times in PBS and uncoated surfaces were blocked with PBS containing $2 \%$ heat-inactivated $B S A$ for $1 \mathrm{~h}$ at $37^{\circ} \mathrm{C}$. The plates were rinsed again, and $5 \times 10^{4}$ cells, prepared by $0.25 \%$ trypsin-EDTA treatment, were added to each well in $1 \mathrm{ml}$ of culture medium. Although the initial cell adhesion efficiency was different depending on the substrates, most of cells became adherent within a few hours, thus giving the same cell numbers. Then, cells were subjected to serum starvation for 24 $h$, which should have brought most of the cells into the G0 phase of the cell cycle. After incubating for $24 \mathrm{~h}$, cell proliferation was assessed by counting cells after trypsinization using a hematocytometer at intervals of $24 \mathrm{~h}$. Cell numbers at $0 \mathrm{~h}$ indicates numbers at $24 \mathrm{~h}$ after initial cell seeding. There was no difference in the initial cell numbers at $0 \mathrm{~h}$ point among different conditions.

\section{Statistical analysis}

The difference between two mean values was analyzed by ANOVA t-test and was considered to be statistically significant when $P<0.05$.

\section{Results}

\section{TGF- $\beta$ induces $\beta$ ig-h 3 expression in RPTECs}

Culture fluid of primary human renal proximal tubular epithelial cells (RPTECs) were analyzed for the Big-h3 protein revealed by Western blotting and by ELISA. The $68 \mathrm{kDa} \beta$ ig-h3 protein was constitutively expressed in RPTECs and markedly increased upon treatment with TGF- $\beta 1$ in a dose-dependent manner (Figure $1 \mathrm{~A}$ and $1 \mathrm{~B}$ ).

Big-h3 mediates adhesion and spreading through two conserved $\alpha 3 \beta 1$ integrin-interacting motifs in RPTEC

Big-h3 (wt) was found to be just as effective as 
A

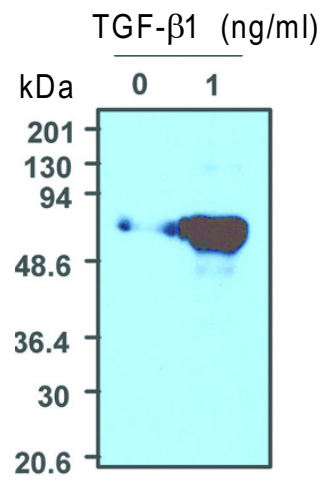

B

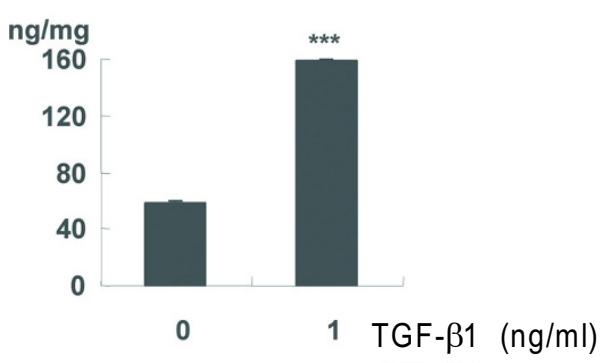

Figure 1. Induction of $\beta$ ig-h3 expression by TGF- $\beta 1$ in RPTECs. Cells were incubated with or without $1 \mathrm{ng} / \mathrm{ml}$ of TGF- $\beta 1$ for $48 \mathrm{~h}$. $\beta \mathrm{ig}-\mathrm{h} 3$ protein levels of cell supernatant were estimated by Western blotting (A) and ELISA (B). Data are presented as mean \pm SD of at least three determinations. ${ }^{*} P<0.05$ compared with $0 \mathrm{ng} / \mathrm{ml}$.

fibronectin in providing RPTEC adhesion and spreading. It was previously demonstrated that each of the second (D-II) and fourth (D-IV) but not the first (D-I) and third (D-III) FAS1 domains has a $\alpha 3 \beta 1$ integrin interacting motif to mediate human corneal epithelial cell adhesion (Kim et al., 2000b). As expected, the same motifs mediated RPTEC adhesion. The second and fourth domains were able to support adhesion and spreading of RPTECs (Figure 2).

Like for corneal epithelial cells, two well conserved amino acids, aspartic acid and isoleucine of each of the second and fourth domains were essential for mediating RPTEC adhesion and spreading (Figure 3). Peptides containing the two amino acids, NKDIL and EPDIM were sufficient for supporting RPTEC adhesion and spreading (Figure 4). A well-known cell adhesion peptide, GRGDSP was less effective than NKDIL and EPIDIM in mediating RPTEC adhesion and spreading (Figure 4).

In next experiments, RPTEC adhesion mediated by synthetic peptides, NKDIL and EPDIM were dramatically blocked by function-blocking monoclonal antibodies to $\alpha 3$ and $\beta 1$ integrin subunits (Figure 5). These results suggest that $\beta$ ig-h3 enhances RPTEC adhesion through two $\alpha 3 \beta 1$ integrin-interacting motifs.

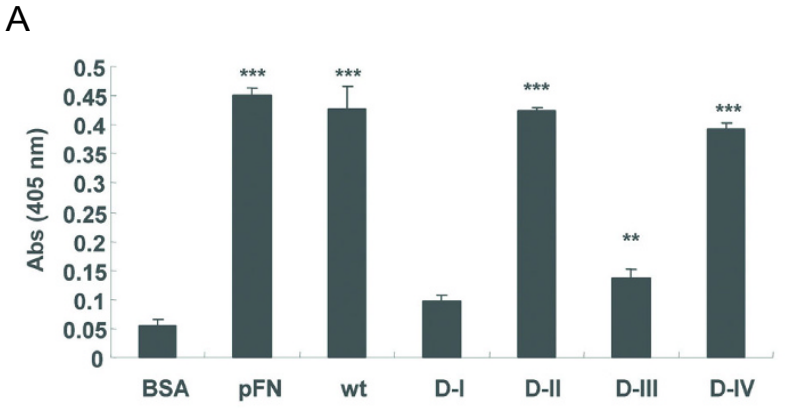

B
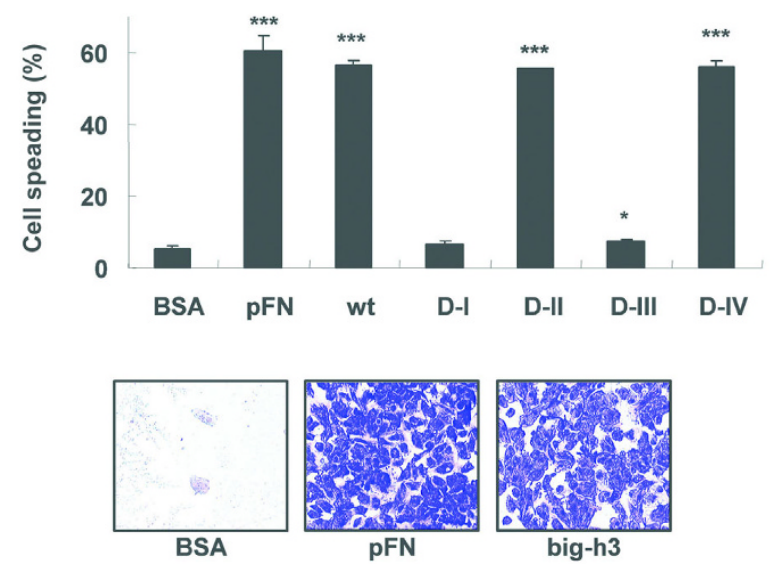

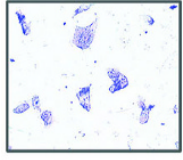

D-I

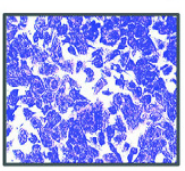

D-II

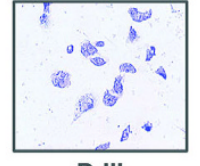

D-III

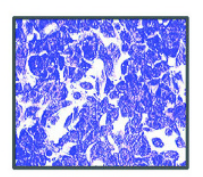

D-IV
Figure 2. $\beta$ ig-h3 mediates adhesion and spreading of RPTECs. Cells were seeded onto surfaces coated with $2 \%$ BSA or each protein (10 $\mu \mathrm{g} / \mathrm{ml})$. After seeding and incubation, cells attached to the surfaces were quantified by hexosaminidase assay (A). After incubation, cells were rinsed with PBS, fixed in $8 \%$ glutaraldehyde, and stained with crystal violet. Cell areas were determined using Image Pro plus software (B). Data are presented as mean \pm SD of triplicate determination from at least three experiments. ${ }^{*} P<0.05,{ }^{* *} P<$ $0.01,{ }^{* * *} P<0.001$ compared with BSA. The abbreviations represent as follows: BSA, bovine serum albumin; pFN, plasma fibronectin; wt, wild type $\beta$ ig-h3; D-I, first fas-1 domain; D-II, second fas-1 domain; D-III, third fas-1 domain; D-IV, fourth fas-1 domain.

\section{Big-h3 enhances RPTEC migration through NKDIL and EPDIM motifs interacting with $\alpha 3 \beta 1$ integrin}

To test whether $\beta$ ig-h3 could mediate RPTEC migration, we employed transwell plates for migration assay. Cells were seeded onto transwells coated with either wild-type $\beta$ ig-h3 or BSA. As is shown in Figure $6 \mathrm{~A}$, RPTECs migrated through the filter coated with Big-h3 (wt), D-II, and D-IV at $6 \mathrm{~h}$ after seeding 
A

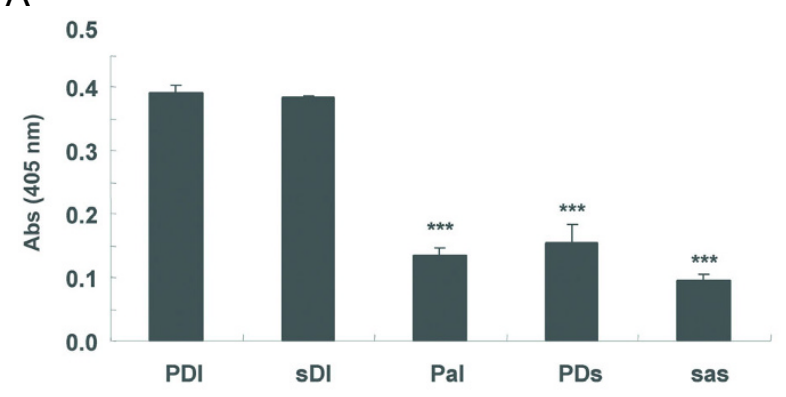

B
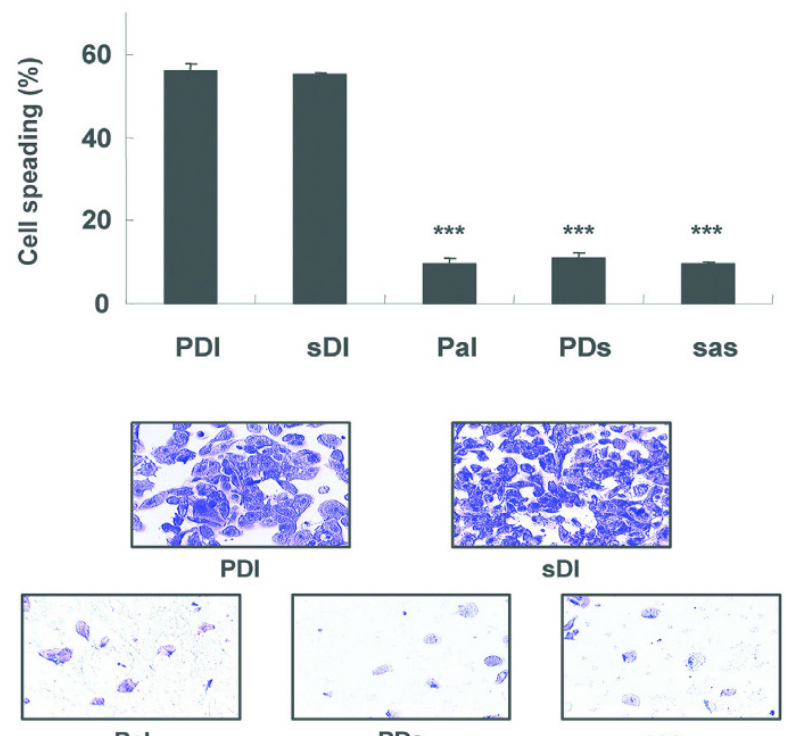

PDs

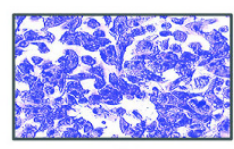

sDI

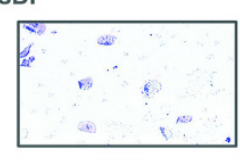

sas

Figure 3. Aspartic acid and isoleucine in fourth domain of $\beta i g-h 3$ are responsible for RPTEC adhesion and spreading. Ten $\mu \mathrm{g} / \mathrm{ml}$ of each protein was used for coating surface. After seeding and incubation, cells attached to the surfaces were quantified by hexosaminidase assay (A). After incubation, cells were rinsed with PBS, fixed in $8 \%$ glutaraldehyde, and stained with crystal violet. Cell areas were determined using Image Pro plus software (B). Data are presented as mean $\pm S D$ of triplicate determination from at least three experiments. ${ }^{* * *} P<0.001$ compared with PDI. The abbreviations used are same to the above.

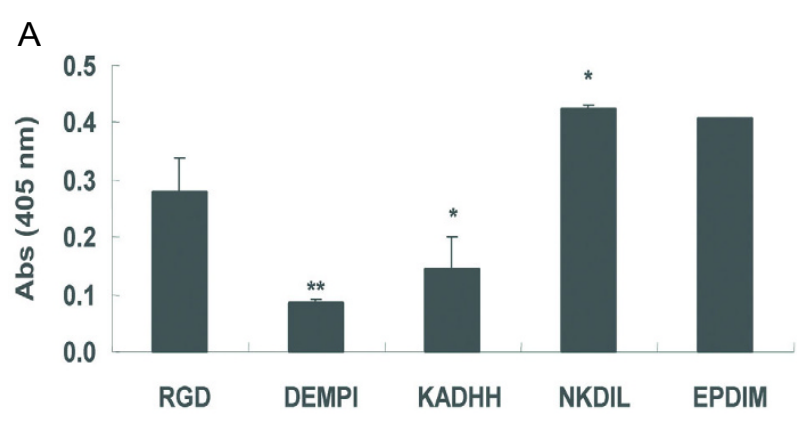

B
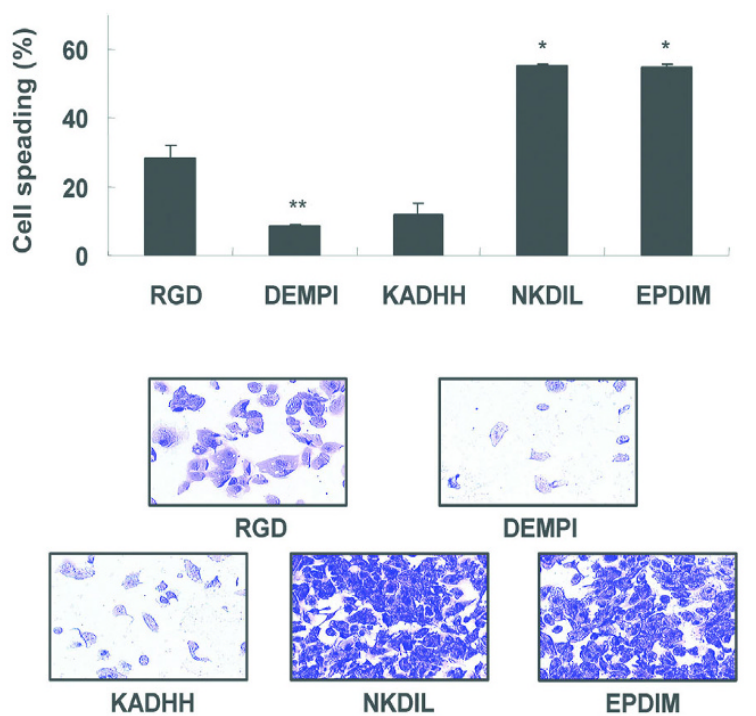

Figure 4. Two conserved $\alpha_{3} \beta_{1}$ integrin-interacting motifs mediate RPTEC adhesion and spreading. One hundred $\mu \mathrm{M}$ of each peptide was used for the coating surface. After seeding and incubation, cells attached to the surfaces were quantified by hexosaminidase assay (A). After incubation, cells were rinsed with PBS, fixed in $8 \%$ glutaraldehyde, and stained with crystal violet. Cell areas were determined using Image Pro plus software (B). Data are presented as mean \pm $\mathrm{SD}$ of triplicate determination from at least three experiments. ${ }^{*} P<$ $0.05,{ }^{* *} P<0.01$ compared with RGD.

\section{Abs (405 nm)}

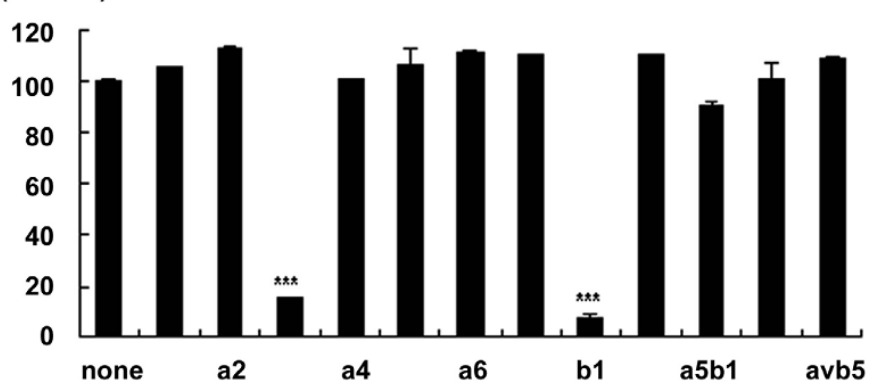

Figure 5. Anti-integrin function-blocking antibodies $\alpha 3$ and $\beta 1$ block the adhesion of RPTECs on $\beta$ ig-h3. Before seeding cells were preincubated with each antibody and cells attached to the surfaces were quantified by hexosaminidase assay. Data are presented as mean $\pm \mathrm{SD}$ of triplicate determination from at least three experiments. 


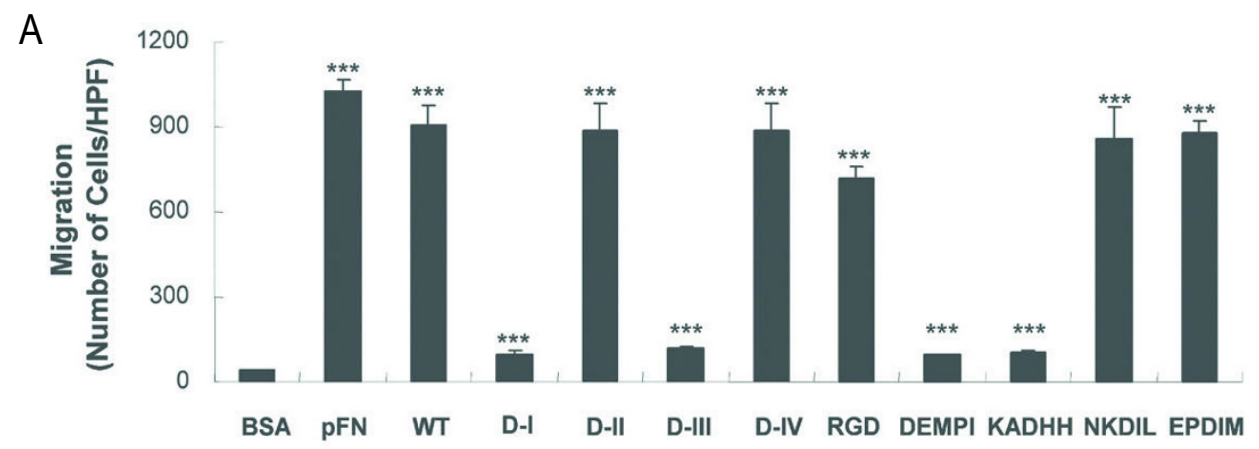

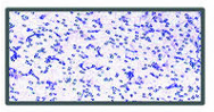

BSA

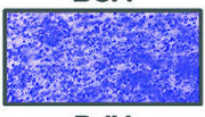

D-IV

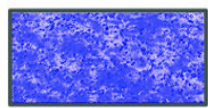

pFN

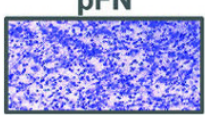

GRGDSP

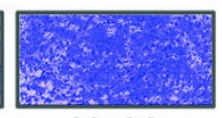

big-h3

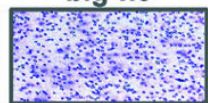

DEMPI

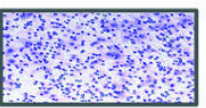

D-I

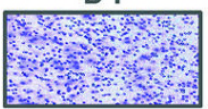

KADHH

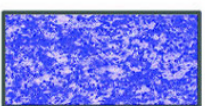

D-II

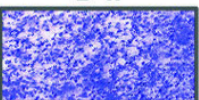

NKDIL

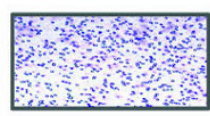

D-III

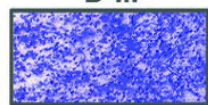

EPDIM

B

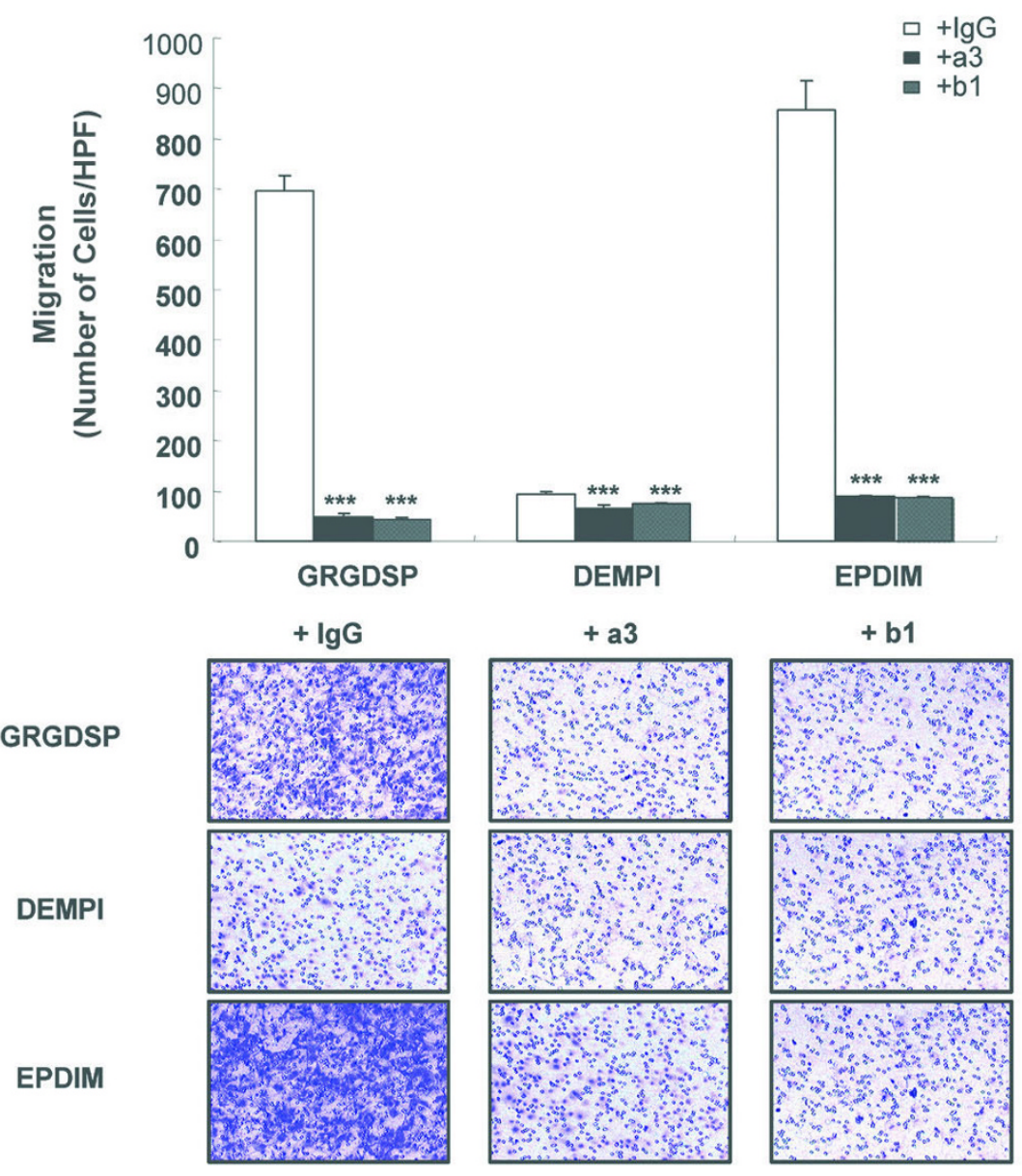

Figure 6. $\beta$ ig-h3 enhances RPTEC migration through NKDIL and EPDIM motifs interacting with $\alpha 3 \beta 1$ integrin. Migration of RPTECs on each $\beta$ ig-h3 protein $(10 \mu \mathrm{g} / \mathrm{ml})$ or synthetic peptide $(100 \mu \mathrm{M})$ was assayed using a transwell. In some experiments cells were preincubated with each antibody before seeding (B). Cell migration was quantified by counting migrated cells in nine microscopic fields. The results were calculated from three separate experiments with duplicate performance in each experiment. Data are presented as mean $\pm S D$. ${ }^{* * *} P<0.001$ compared with BSA (A) or with $\lg G(B)$. The abbreviations used are same to the above. 
A

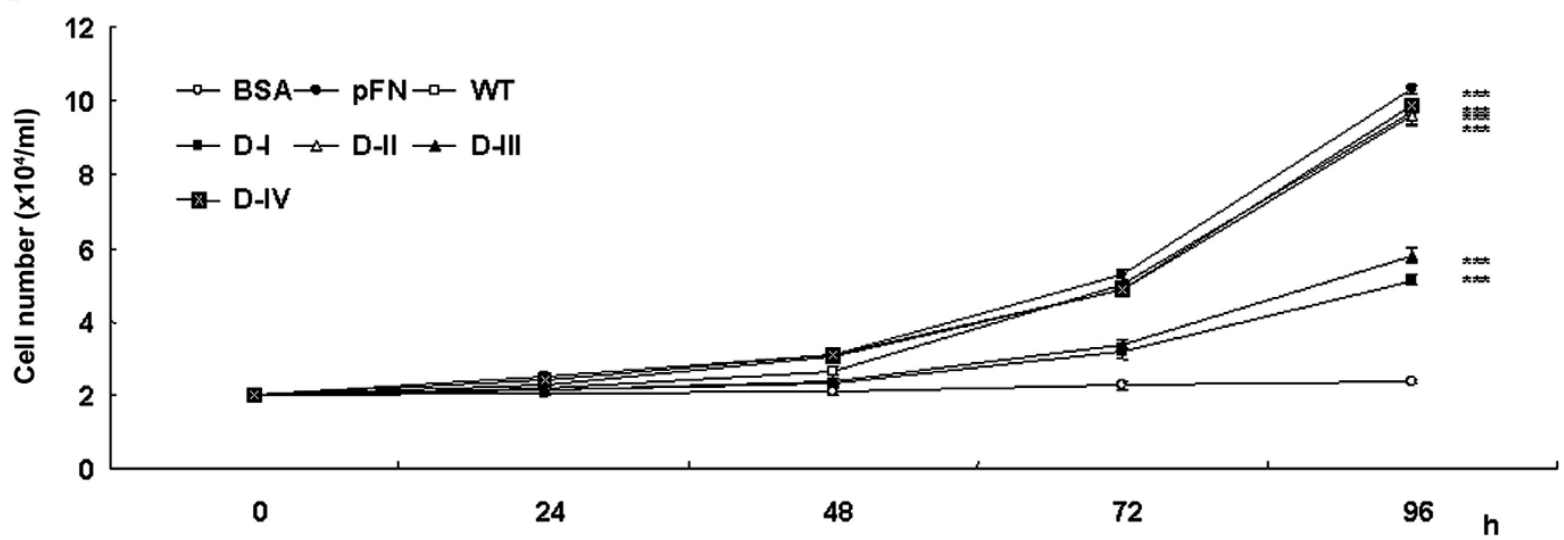

B

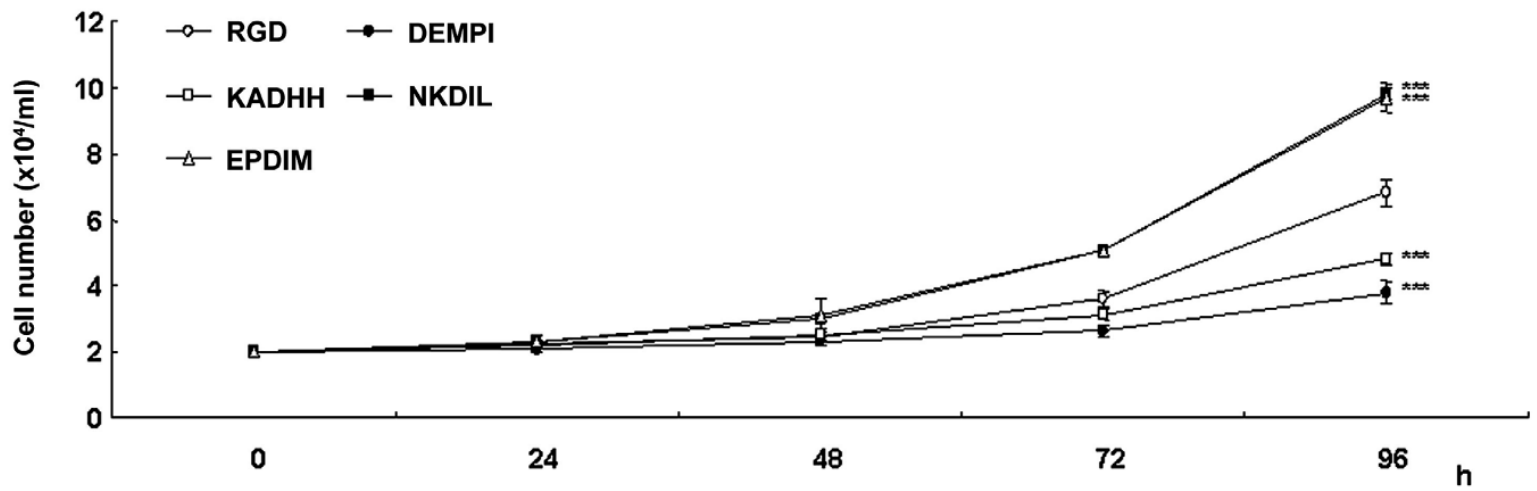

Figure 7. $\beta$ ig-h3 enhances RPTEC proliferation through NKDIL and EPDIM motifs. Ten $\mu \mathrm{g} / \mathrm{ml}$ of each protein (A) or $100 \mu \mathrm{M}$ of each synthetic peptide (B) was used for coating. Synchronized cells by serum starvation were seeded in coated culture plates. After incubation for indicated time the cell number was measured. The results were calculated from three separate experiments with duplicate performance in each experiment. Data are presented as mean $\pm \mathrm{SD}$. ${ }^{* *} P<0.001$ compared with BSA (A) or RGD (B). The abbreviations used are same to the above.

whereas very little migration was observed on the filter coated with BSA. Synthetic peptides, NKDIL and EPDIM were also effective as much as $\beta$ ig-h3 proteins. Function- blocking monoclonal antibodies against $\alpha 3$ and $\beta 1$ integrin subunits were able to block RPTEC migration mediated by EPDIM almost completely. DEMPI, the scrambled control peptide of EPDIM could neither affect RPTEC migration nor showed changes in their effect upon treatment with antibodies (Figure 6B).

\section{$\beta$ ig-h3 enhances RPTEC growth through NKDIL and EPDIM motifs}

In order to determine that $\beta$ ig-h3 is also supportive for RPTEC growth, RPTECs were seeded on each protein or peptides as is shown in Figure 7 and their growth was measured. Synchronized RPTECs by serum starvation were plated on the surface coated with each of proteins and peptides. There were significant differences in the growth rate according to proteins and peptides. As shown in Figure 7A and $B$, RPTECs plated on wild-type $\beta i g-h 3$ (wt), the second FAS1 domain (D-II) and the fourth FAS1 domain (D-IV) showed marked increase in cell number compared to bovine serum albumin, D-I, and D-III. In addition, as is shown in Figure 7B, two peptides, NKDIL and EPDIM were sufficiently supportive for cell growth whereas DEMPI and KADHH were not. Again, the GRGDSP peptide was not as effective as NKDIL and EPDIM.

\section{Discussion}

Big-h3 was first identified as a gene induced in A549 cells after treatment with TGF- $\beta$ (Skonier et al., 1992) and was subsequently reported to be induced by TGF- $\beta$ in several cell types (Sharma and Ziyadeh, 1995). It has been reported to be present in several tissues (LeBaron et al., 1995; O'Brien et al., 1995; Gibson et al., 1997; Rawe et al., 1997; Gilbert et al., 
1998). Although biological roles of $\beta$ ig-h3 are largely unknown, it has been suggested that it may act as a cell adhesion substrate, regulate cell growth, interconnect other matrix components, and transduce TGF- $\beta$-mediated signaling (Skonier et al., 1992; Lebaron et al., 1995; Gibson et al, 1997; Kim et al., 2000).

The data presented here shows that $\beta$ ig-h3 is produced by RPTECs, and its expression is induced by TGF- $\beta$ treatment. The previous report demonstrate that $\beta$ ig-h3 protein was predominantly expressed in close association with the basement membrane of the proximal tubule S3 segment in both normal and diabetic rat kidneys. Western blot analysis also showed that $\beta$ ig-h3 is detected only in the kidney cortex and the outer stripe of the outer medulla but not in the inner stripe of the outer medulla or the inner medulla (Lee et al., 2003). Those observations are consistent with the other report showing that $\beta$ ig-h3 mRNA is mainly localized to the pars recta (S3 segment) of the proximal tubules of the rat kidney (Gilbert et al., 1998). Despite the physiologic meaning why ßig-h3 expression is restricted to the proximal tubule is not clear so far, the fact that $\beta$ ig-h3 expression is closely associated with the basement membrane suggests that $\beta$ ig-h3 may mediate tubular epithelial cell adhesion and migration in both physiological and pathological conditions.

Since $\beta$ ig-h3 have been reported to mediate cell adhesion in several cell types including skin fibroblasts (LeBaron et al., 1995), corneal epithelial cells (Rawe et al., 1997; Kim et al., 2000b), chondrocytes (Ohno et al., 1999), and keratinocytes (Bae et al., 2002), it is reasonable to test the ability of $\beta$ ig-h3 to mediate RPTEC adhesion. The result shows that Big-h3 supported RPTEC adhesion and spreading. Previously we (Kim et al., 2000b) have identified that $\beta i g-h 3$ has two $\alpha 3 \beta 1$ integrin-interacting motifs, NKDIL and EPDIM. There are reports showing that $\alpha 3 \beta 1$ integrin is important for kidney development (Kreidberg, 2000; Kreidberg and Symons, 2000) and tubulogenesis (Jiang et al., 2001). Based on these evidences RPTECs might adhere to $\beta$ ig-h3 through the $\alpha 3 \beta 1$-integrin interacting motifs. The present study revealed that the second and fourth domains out of four FAS1 domains were active in mediating RPTEC adhesion, and aspartic acid and isoleucine were responding amino acids within the domains as previously identified. Two synthetic peptides, NKDIL and EPDIM were sufficient to support RPTEC adhesion. The result also demonstrated that $\beta$ ig-h3-mediated adhesion was blocked by function-blocking antibodies against $\alpha 3$ and $\beta 1$ integrin subunits. These data suggest that $\beta$ ig-h3 serves as a substrate for RPTECs through interacting with $\alpha 3 \beta 1$ integrins.

As the tubular epithelium regenerated, cells would flatten, spread, and migrate over denuded areas of the basement membrane (Zuk et al., 1998). Keratinocyte migration is an essential process during early wound healing and has been shown to be dramatically influenced by extracellular matrix components (Takashima and Grinnel, 1984; Sugita et al., 1987; Guo et al., 1990; Zang and Kramer, 1996; Putnins et al., 1999). Kidney injury is repaired by inflammatory and non-inflammatory mechanisms, with the extent of recovery based on severity of the insult. Certain forms of recovery after acute tubular necrosis involve extensive remodeling of the proximal tubule, where integrity of the basement membrane is required for successful repair (Mene et al., 2003). Because Big-h3 was expressed predominantly in basement membrane of proximal tubules, Big-h3 might function to stimulate RPTEC migration during tubular regeneration. The present results showed that $\beta$ ig-h3 and its second and fourth domains markedly enhanced RPTEC migration. Like the results of adhesion assays RPTEC migration was also enhanced on NKDIL and EPDIM through the interation with $\alpha 3 \beta 1$ integrin by using the function-blocking antibodies against $\alpha 3$ and $\beta 1$ integrins.

In addition to the roles of $\beta$ ig-h3 in adhesion, spreading and migration, $\beta \mathrm{ig}-\mathrm{h} 3$ may stimulate proliferation of RPTECs. The results demonstrate that $\beta$ ig-h3 was able to stimulate cell proliferation through its two $\alpha 3 \beta 1$ integrin-interacting motifs. Other wellknown cell adhesion substrates such as laminins also have been shown to stimulate cell proliferation (Panayotou et al., 1989; Mortarini et al., 1995; Gonzales et al., 1999).

In conclusion, the present study demonstrated that Big-h3 mediates adhesion, spreading, migration and proliferation of RPTECs through the interaction with $\alpha 3 \beta 1$ integrin. This suggests that $\beta$ ig-h3 may play an important role in maintenance and regeneration of proximal tubular epithelium.

\section{Acknowledgement}

This work was supported by a program of National Research Laboratory (M10318000036-03J0000-01410) and the research promoting grant from the Keimyung University Dongsan Medical Center.

\section{References}

Bae J-S, Lee S-H, Kim J-E, Choi J-Y, Park R-W, Park J-Y, Park H-S, Sohn Y-S, Lee D-S, Lee EB, Kim I-S. Big-h3 supports keratinocytes adhesion, migration, proliferation through $\alpha 3 \beta 1$ integrin. Biochem Biophys Res Commun 2002; 294:940-8

Gibson MA, Kumaratilake JS, Cleary EG. Immunohisto- 
chemical and ultrastructural localization of MP78/70 (Big-h3) in extracellular matrix of developing and mautre bovine tissues. J Histochem Cytochem 1997;45:1683-96

Gilbert RE, Wilkinson-Berka JL, Johnson DW, Cox A, Soulis T, Wu LL, Kelly DJ, Jerums G, Pollock CA, Cooper, ME. Renal expression of transforming growth factor- $\beta$ inducible gene-h3 ( $\beta$ ig-h3) in normal and diabetic rats. Kidney Int 1998;54:1052-62

Gonzales M, Haan K, Baker SE, Fitchmun M, Todorov I, Weitzman S, Jones JC. A cell signal pathway involving laminin-5, $\alpha 3 \beta 1$ integrin, mitogen-activated protein kinase can regulate epithelial cell proliferation. Mol Bio Cell 1999;10:25970

Guo M, Toda K, Grinnell F. Activation of human keratinocyte migration on type I collagen and fibronectin. J Cell Sci 1990;96:197-2

Jiang ST, Chiu SJ, Chen HC, Chuang WJ, Tang MJ. Role of $\alpha 3 \beta 1$ integrin in tubulogenesis of Madin-Darby canine kidney cells. Kidney Int 2001;59:1770-8

Kim J-E, Kim E-H, Han E-H, Park R-W, Park I-H, Jun S-H, Kim J-C, Young MF, Kim I-S. A TGF- $\beta$-inducible cell adhesion molecule, $\beta i g-h 3$, is downregulated in melorheostosis and involved in osteogenesis. J Cell Biochem 2000a;77: 169-17

Kim J-E, Kim S-J, Lee B-H, Park R-W, Kim K-S, Kim I-S. Identification of motifs for cell adhesion within the repeated domains of transforming growth factor- $\beta$-induced gene, Big-h3. J Biol Chem 2000b;275:30907-15

Kim J-E, Park R-W, Choi J-Y, Bae Y-C, Kim K-S, Joo C-K, Kim I-S. Molecular properties of wild type and mutant Big-h3 proteins. Invest Ophthalmol Vis Sci 2002;43:656-61

Kreidberg JA. Functions of $\alpha 3 \beta 1$ integrin. Curr Opinion Cell Biol 2000;12:548-53

Kreidberg JA, Symons JM. Integrins in kidney development, function, disease. Am J Physiol Renal Physiol 2000;279: F233-F242

Langham RG, Egan MK, Dowling JP, Gilbert RE, Thomson NM. Transforming growth factor- $\beta 1$ and tumor growth factor- $\beta$-inducible gene-h3 in nonrenal transplant cyclosporine nephropathy. Transplantation 2001;72:1826-9

LeBaron RG, Bezverkov KI, Zimber MP, Pavelec R, Skonier $J$, Purchio AF. $\beta I G-H 3$, a novel secretory protein inducible by transforming growth factor- $\beta$, is present in normal skin and promotes the adhesion and spreading of dermal fibroblasts in vitro. J Invest Dermatol 1995;104:844-8

Lee EH, Seo MY, Hwang KH, Kim JE, Kim JH, Joo CK: Overexpression of the transforming growth factor-betainducible gene $\beta$ ig-h3 in anterior polar cataracts. Invest Ophthalmol Vis Sci 2000;41:1840-5
Lee S-H, Bae J-S, Park S-H, Lee B-H, Park R-W, Choi J-Y, Park J-Y, Kim Y-L, Kwon T-H, Kim I-S. Expression of TGF- $\beta$-induced matrix protein $\beta$ ig-h3 is up-regulated in the diabetic rat kidney and human proximal tubular epithelial cells treated with high glucose. Kidney Int 2003;64:1012-21

Mene P, Polci R, Festuccia F. Mechanisms of repair after kidney injury. J Nephrol 2003;16:186-95

Mortarini R, Gismondi A, Maggioni A, Santoni A, Herlyn M, Anichini A. Mitogenic activity of laminin on human melanoma and melanocytes: different signal requirements and role of beta 1 integrins. Cancer Res 1995;55:4702-10

O'Brien ER, Bennet KL, Garvin MR, Zderic TW, Hinohara $T$, Simpson JB, Kimura T, Nobuyoshi M, Mizgala $H$, Purchoi A, Schwartz M. Big-h3, a transforming growth factor$\beta$-inducible gene, is overexpressed in atherosclerotic and restenotic human vascular lesions. Arterioscler Thromb Vasc Biol 1996;16:576-5

Ohno S, Noshiro M, Makihira S, Kawamoto T, Shen M, Yan $\mathrm{W}$, Kawashima-Ohya $\mathrm{Y}$, Fujimoto $\mathrm{K}$, Tanne $\mathrm{K}$, Kato $\mathrm{Y}$. RGD-CAP (Big-h3) enhances the spreading of chondrocytes and fibroblasts via integrin $\alpha 1 \beta 1$. Biochim Biophys Acta 1999;1451:196-219

Panayotou G, End P, Aumailley M, Timpl R, Engel J. Domains of laminin with growth factor acitivity. Cell 1989;56: 93-101

Putnins EE, Firth JD, Lohachitranont A, Uitto VJ, Larjava $\mathrm{H}$. Keratinocyte growth factor (KGF) promotes keratinocyte cell attachment and migration on collagen and fibronectin. Cell Adhesion Comm 1999;7:211-2

Rawe IM, Zhan Q, Burrows R, Bennett K, Cintron C. Beta-ig, Molecular cloning and in situ hybridization in corneal tissues. Invest Ophthalmol Vis Sci 1997;38:893-9

Sharma K, Ziyadeh FN. The emerging role of transforming growth factor- $\beta$ in kidney diseases. Am J Physiol 1994;266: F829-F842

Skonier J, Noshiro M, Madisen L, Bennett K, Plowman GD, Purchio AF. cDNA cloning and sequence analysis of big-h3, a novel gene induced in a human adenocarcinoma cell line after treatment with transforming growth factor- $\beta$. DNA Cell Biol 1992;7:511-22

Sugita T, Huang CC, Abramson M. The effect of fibronectin on the migration of keratinocytes. Acta Otolaryngol 1987; 104:521-5

Takashima A, Grinnell F. Fibronectin-mediated keratinocyte migration and initiation of fibronectin receptor function in vitro. J Invest Dermatol 1984;85:304-8

Zhang K, Kramer RH. Laminin 5 deposition promotes keatinocyte motility. Exp Cell Res 1996;227:309-22 